\title{
Entre a sedução estética e a densidade introspectiva
}

\author{
José Pedro Serra
}

Titulo: 0 jogador (1867). Autor: Fiódor Dostoievski. Adaptação: Emilia Costa. Encenação: Gonçalo Amorim. Assistência de encenação e dramaturgia: Ana Bigotte Vieira. Assistência de encenação e movimento: Vânia Rovisco. Cenografia: Rita Abreu. Assistência de cenografia: Raquel Albino. Figurinos e adereços: Ana Limpinho e Maria João Castelo. Música original: Paulo Furtado e Rita Redshoes. Desenho de luz: José Manuel Rodrigues. Sonoplastia: Sérgio Milhano. Video: Frederico Lobo. Interpretação: António Fonseca, Carla Galvão, Carla Maciel, Duarte Guimarães, Iris Cayatte, Joana de Verona, João Villas Boas, Mónica Garnel, Nicolas Brites, Raquel Castro, Romeu Costa, Vânia Rovisco. Produção: São Luiz Teatro Municipal. Local e data de estreia: São Luiz Teatro Municipal, Lisboa, 5 de Maio de 2011.
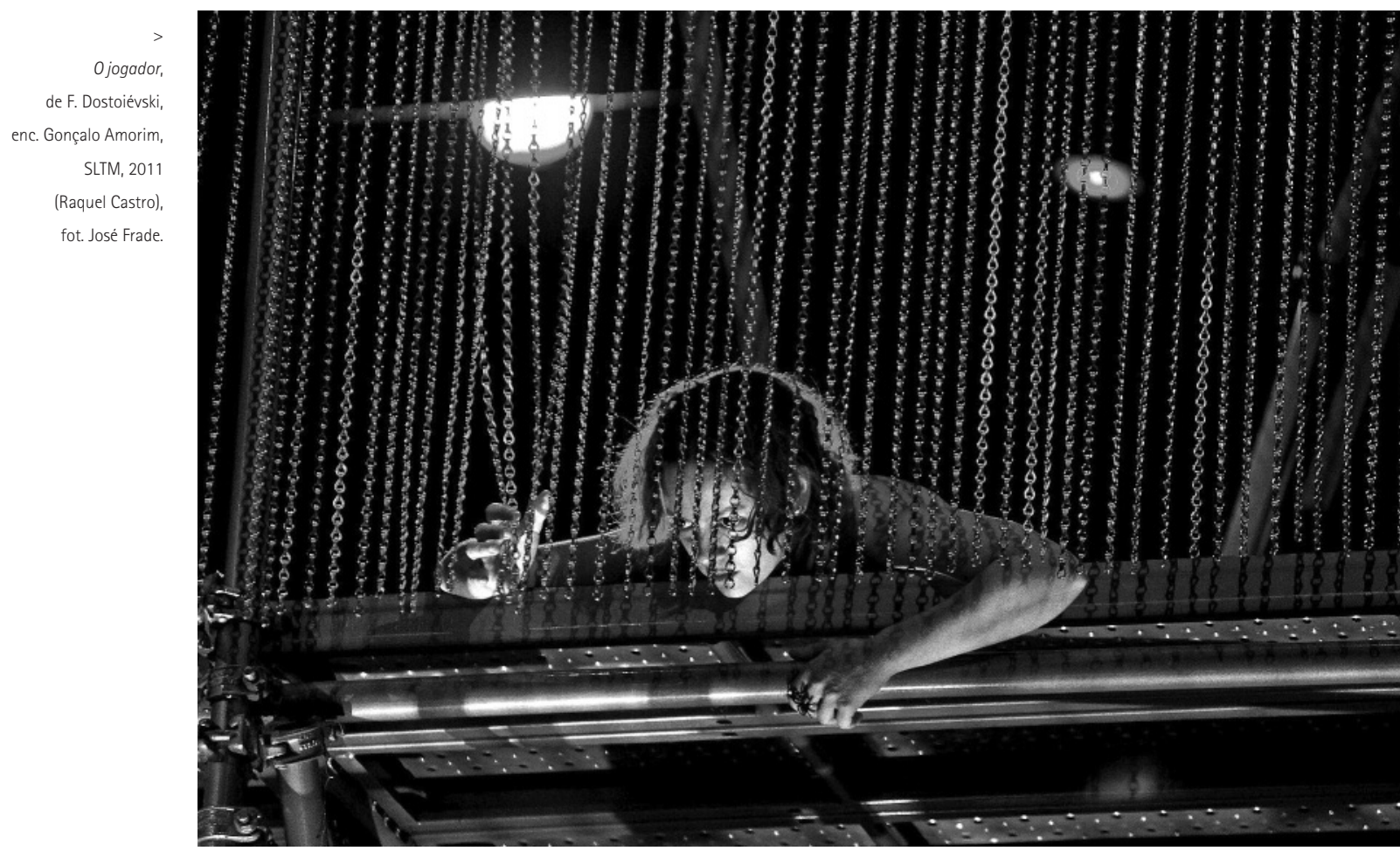

Com encenação de Gonçalo Amorim, subiu ao palco do São Luiz Teatro Municipal 0 jogador de F. Dostoievski, numa adaptação de Emilia Costa. Magnífico e oportuno texto, quer pela qualidade literária, quer pela proximidade existencial em que nos revemos, a dramatização desta

José Pedro Serra

é professor do

Departamento de

Estudos Clássicos da

Faculdade de Letras da

Universidade de Lisboa

e investigador do

Centro de Estudos

Clássicos da mesma

Faculdade. peça, porém, levanta desde logo alguns difíceis problemas. $\mathrm{Na}$ obra do autor russo, a complexidade e a densidade das personagens, o dramatismo da teia que as vai enleando e perdendo, teia pelas circunstâncias e por elas próprias consentida, talvez mesmo desejada, constroem-se e revelam-se a partir de descrições várias e de uma fina análise dos movimentos da alma - muitas vezes realizada introspectivamente pelas próprias personagens, na qual desempenham lugar de relevo os vínculos afectivos que a ligam à paixão, ao desespero, à solidão. Erguida nesta fervente mas distante reflexão das e sobre as personagens como traduzir estes murmúrios da alma "dramaticamente" isto é, em linguagem teatral, sem que o sentido e intensidade dos dilemas e dos tumultos afectivos da psique se percam? É, porventura, esta pergunta que antes de mais anima o olhar daquele que se debruça sobre este espectáculo. Ao que tudo indica, esta mesma preocupação esteve presente, e de várias maneiras, na construção do espectáculo. Antes de mais, a preocupação pela referida teatralidade deste universo descritivo e introspectivo notase na modulação dos diálogos, isto é, na adaptação, cujo objectivo me parece ser o de dar a ver, quer explicitamente quer marginalmente, as tensões patentes e latentes que atravessam a obra. Embora dificil, creio que, na generalidade, o objectivo foi conseguido. Inclusivamente, 

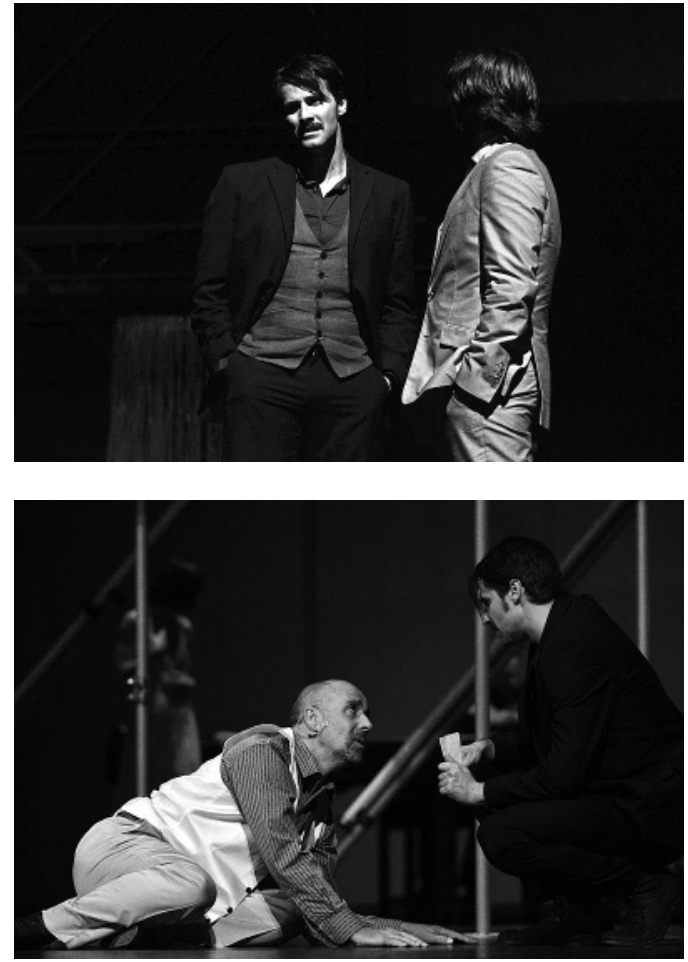

a transformação das jovens e de algum modo esquecidas filhas do general, aqui transformadas em libidinosas adolescentes que se vingam em devaneios eróticos da solidão que as mina, acaba por ganhar, no último episódio, coerência e legitimidade.

Além dos cuidados colocados na adaptação, julgo ter percebido dois outros processos a que Gonçalo Amorim recorre para dar, no palco, a expressão fiel da descrita intensidade afectiva. 0 primeiro consiste na inclusão da leitura de excertos da obra, leitura essa que constitui um ponto de contacto com a natureza da prosa de Dostoievski e que pode auxiliar à compreensão dos oceânicos sentimentos que jazem na margem silenciosa das palavras ditas. 0 segundo processo relaciona-se não apenas com a escolha dos cenários, mas com a linguagem corporal, verdadeiro elemento complementar para a percepção do universo representado. A atenção colocada no movimento dos actores, no ritmo e na plasticidade dos gestos é imensa e testemunha a relevância destes elementos na apreensão do sentido global da peça. E tocamos aqui o aspecto decisivo desta representação. Reconheçamos, previamente, que há nesta encenação um fresco entusiasmo juvenil que, à força de querer ser fiel, completo e exaustivo, prolonga excessivamente a acção, fazendo-a demorar repetidamente. Não me refiro propriamente à construção em episódios, mas ao tempo, excessivamente longo, que os veste e os demora - algumas vezes repetindo o que já fora perceptível. 0 risco é que o resultado deste excesso,

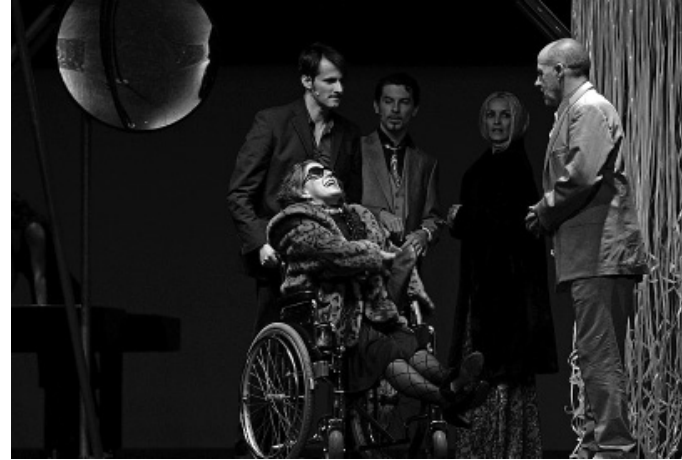

em lugar de tornar mais densa e profunda a acção, pode debilitá-la. A questão essencial - e a mais interessante não está, todavia, no generoso "exagero" que, talvez com beneficio, pudesse ter sido moderado. A questão central está no compromisso entre a sedução plástica da encenação, apoiada na beleza formal do espaço e do gesto, e o dramatismo pungente de várias personagens que, à sua maneira, se vão esgotando e perdendo, como se elas próprias mais não fossem do que golpes casuais de uma roleta que os joga - é, aliás, na aguda consciência do desastre que envolve as suas vidas que o jogo,

ambiguamente, é simultaneamente adivinhado caminho de desgraça e irracional esperança de redenção. A beleza plástica da encenação e da representação - para o que muito contribui a música e o conjunto de actores - está presente em muitos momentos, a começar pela magnífica cortina dourada que marca decisivamente o espaço da acção. Esta qualidade plástica, em largos momentos conseguida, possui, no entanto, duas vertentes; por um lado, ela provoca a visão seduzida, o vínculo que une a visão do espectador à exterioridade da forma; por outro lado, ao agarrar o espectador ao colorido encanto das vestes e das formas, ameaça prendê-lo numa deliciada exterioridade, afastada do intenso drama interior das personagens que aí "se jogam". Esta é a fértil tensão que anima a encenação de Gonçalo Amorim. Momentos há em que essa conjugação se realiza perfeitamente, como nas belas cenas do segundo episódio em que um silencioso riso vindo do alto cai sobre as "pequenas cenas da vida". Os belos e bem conseguidos movimentos lentos e ao mesmo tempo levemente histriónicos desses seres femininos (neles há qualquer coisa de Parcas ou de bruxas...) emprestam às cenas uma força maior. Em outros momentos, não sendo essa conjugação tão evidente, pode o espectador distrair-se no criativo jogo de movimentos e de luzes, esquecendo o drama que à sua frente se desenrola. Esse é o risco que desponta aqui e ali. Importa, porém, dizer que, mesmo nestes momentos, o caminho seguido é sempre interessante e revela a argúcia interpretativa de quem o desenhou.
$<$

$\checkmark$

O jogador,

de F. Dostoiévski, enc. Gonçalo Amorim SLTM, 2011

(< Romeu Costa e Duarte Guimarães; > Joana de Verona, Romeu Costa, Mónica Garnel, João Villas Boas, Carla Maciel e António Fonseca; $\checkmark$ António Fonseca e Romeu Costa), fot. José Frade. 